\title{
Daniel Ménager, La Renaissance et la nuit
}

\section{Dario Cecchetti}

\section{(2) OpenEdition}

\section{Journals}

\section{Edizione digitale}

URL: http://journals.openedition.org/studifrancesi/30061

DOI: 10.4000/studifrancesi.30061

ISSN: 2421-5856

\section{Editore}

Rosenberg \& Sellier

\section{Edizione cartacea}

Data di pubblicazione: 1 avril 2006

Paginazione: 140-141

ISSN: 0039-2944

\section{Notizia bibliografica digitale}

Dario Cecchetti, «Daniel Ménager, La Renaissance et la nuit», Studi Francesi [Online], 148 (XLX | I) | 2006,

online dal 30 novembre 2015, consultato il 19 avril 2021. URL: http://journals.openedition.org/ studifrancesi/30061 ; DOI: https://doi.org/10.4000/studifrancesi.30061

\section{Questo documento è stato generato automaticamente il 19 avril 2021.}

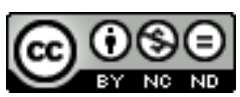

Studi Francesi è distribuita con Licenza Creative Commons Attribuzione - Non commerciale - Non opere derivate 4.0 Internazionale. 


\title{
Daniel Ménager, La Renaissance et la nuit
}

\author{
Dario Cecchetti
}

\section{NOTIZIA}

DANIEL MÉNAGER, La Renaissance et la nuit, Genève, Droz («Les seuils de la modernité», vol. 10), 2005, pp. 270.

Questo bel libro di critica tematica si propone di ricostruire il concetto (e l'immaginario) della notte nella civiltà letteraria e nell'iconologia del Rinascimento, a ridosso di un interessante convegno tenuto a Clermont-Ferrand nel 2000 (Penser la nuit: $X V^{e}-X V I I^{e}$ siècle, Paris, Champion, 2003). In particolare, il saggio di D. Ménager contrasta alla concezione corrente - soprattutto negli storici delle mentalità - di un immaginario notturno rinascimentale associato soltanto alla negatività e alla paura. Dalle analisi che spaziano da Petrarca a san Giovanni della Croce, attraverso una repertoriazione di testi letterari e filosofici e attraverso icone emblematiche, quali la Melancolia di Dürer o la Notte di Michelangelo, vediamo la notte segno di positività: i poeti del Rinascimento trovano in essa il momento della pacificazione interiore, gli scienziati (come Galileo) hanno atteso che la notte si accendesse di stelle, i mistici (come Juan de la Cruz) hanno cercato nella notte le vie oscure del desiderio di Dio. Un'indagine che mette in atto strumenti di comparatistica, abbraccia la letteratura e l'arte di ambito italiano, francese, inglese, tedesco e spagnolo, facendo interagire l'immaginario di Petrarca e Sannazaro, di Ronsard, Belleau e Du Bartas, di Tasso, Shakespeare e Cervantes. Allo studio dell'immaginario letterario (chap. II: Imaginaire, pp. 65-108) si accompagna una lettura iconologica esemplare di quadri del grande manierismo europeo (chap. V: Nocturnes, 193-231: in un libro così preciso segnaliampo la svista tipografica di uno scambio di impaginazione di due immagini, un notturno di Mantegna e uno di Tintoretto invertiti alle pp. 246-247). Si accompagna soprattutto un panorama delle riflessioni filosofiche e religiose sulla notte (chap. I: Cosmologies, pp. 15-63; chap. III: La chouette de Minerve, pp. 109-150; chap. IV: Noche oscura, noche serena, pp. 151-191). In 
questo affermare, contro il parere degli storici delle mentalità (vedi Delumeau), la positività della notte rinascimentale, Ménager sottolinea come la notte cupa, inquietante, malefica, appartenga più alla cultura popolare e al folklore, mentre le testimonianze della letteratura e dell'arte portano piuttosto a una visione di notte benefica. Il merito maggiore, tuttavia, del lavoro che qui segnaliamo consiste non tanto nel registrare testimonianze contrastanti, quanto nel comprendere la diversità di livelli antropologici e la molteplicità di fonti da cui la notte - realtà naturale e metafora deriva una polisemia di fondo. 